\title{
Bi-orienting chromosomes: acrobatics on the mitotic spindle
}

\author{
Tomoyuki U. Tanaka
}

Received: 30 April 2008 /Revised: 5 June 2008 / Accepted: 7 June 2008 / Published online: 2 August 2008

(C) The Author(s) 2008

\begin{abstract}
To maintain their genetic integrity, eukaryotic cells must segregate their chromosomes properly to opposite poles during mitosis. This process mainly depends on the forces generated by microtubules that attach to kinetochores. During prometaphase, kinetochores initially interact with a single microtubule that extends from a spindle pole and then move towards a spindle pole. Subsequently, microtubules that extend from the other spindle pole also interact with kinetochores and, eventually, each sister kinetochore attaches to microtubules that extend from opposite poles (sister kinetochore bi-orientation). If sister kinetochores interact with microtubules in wrong orientation, this must be corrected before the onset of anaphase. Here, I discuss the processes leading to biorientation and the mechanisms ensuring this pivotal state that is required for proper chromosome segregation.
\end{abstract}

\section{Introduction}

In trapeze acrobatics, performers use two wired swings, each hung from ceiling, and skillfully jump from one swing to the other with perfect timing. Such acrobatics require elaborate training and, if performed splendidly, win much applause. However, similar acrobatics are secretly performed by chromosomes within our cells, without acknowledgement or applause. Chromosomes use microtubules, instead of wired swings, and often change their associated micro-

Communicated by E.A. Nigg

T. U. Tanaka $(\bowtie)$

Wellcome Trust Centre for Gene Regulation \& Expression,

College of Life Sciences, University of Dundee,

Dundee, Scotland

e-mail: t.tanaka@lifesci.dundee.ac.uk tubules until proper association is established. During this process, the main microtubule attachment sites on chromosomes are provided by kinetochores, large protein complexes formed at centromere regions. Prior to the onset of chromosome segregation, sister kinetochores (i.e., a pair of kinetochores generated on sister chromatids) must interact with microtubules extending from opposite spindle poles; this state is called sister kinetochore bi-orientation or amphitelic kinetochores-microtubule attachment. Failure in this process would lead to chromosome missegregation and aneuploidy, which is a hallmark of several human diseases such as cancer and congenital disorders (Hassold and Hunt 2001; Rajagopalan and Lengauer 2004). In this review article, I discuss recent advances in researching the mechanisms ensuring sister kinetochore bi-orientation on the mitotic spindle. In this context, the following topics will also be touched upon briefly_-kinetochore composition and assembly (Cleveland et al. 2003; Maiato et al. 2004a; Westermann et al. 2007; Cheeseman and Desai 2008), the spindle assembly checkpoint (Musacchio and Salmon 2007; Burke and Stukenberg 2008), dynamics of spindle microtubules (Gadde and Heald 2004; Kline-Smith and Walczak 2004; Howard and Hyman 2007), and chromosome biorientation in meiosis (Hauf and Watanabe 2004; Marston and Amon 2004). However, these topics have been reviewed in more detail in the indicated references.

\section{Initial kinetochores-microtubule interaction; lateral attachment evolving to end-on coupling}

In trapeze acrobatics, performers first grab a wired swing with their hands before jumping into the air. Similarly, chromosomes must ensure a secure first contact with microtubules, and this happens in the following cell cycle 
stage. In metazoan cells, microtubule-organizing centers (MTOCs), called centrosomes, locate outside of the nucleus (Azimzadeh and Bornens 2007); therefore, microtubules extending from MTOCs can interact with kinetochores only after the nuclear envelope is broken down at the beginning of mitosis (prometaphase; this is known as "open" mitosis; Sazer 2005). On the other hand, in many single-cell eukaryotes including budding yeast, the nuclear envelope is not broken down during mitosis (called "closed" mitosis; Winey and O'Toole 2001). In budding yeast, kinetochores are connected to MTOCs (called spindle pole bodies) by microtubules even during G1 phase (Winey and O'Toole 2001; Dorn et al. 2005) and it was actually thought that kinetochores-microtubule interaction might be maintained throughout the cell cycle and never be interrupted. However, it was recently revealed that, upon centromere DNA replication, kinetochores are transiently disassembled, causing centromere detachment from microtubules for 12 min (Kitamura et al. 2007). Subsequently, kinetochores are reassembled and interact with microtubules again.

In yeast and metazoan cells, how do kinetochores initially interact with microtubules? Kinetochores initially attach to the lateral side of a single microtubule that extends from either spindle pole (where an MTOC is present; Fig. 1, step 1; Hayden et al. 1990; Rieder and Alexander 1990; Tanaka et al. 2005a). The lateral microtubule surface, known as the lattice, provides much larger contact surface, compared with microtubule tips, thus, contributing to an efficient first encounter with kinetochores. The capture of microtubule lattice by kinetochores was initially discovered in newt lung cells (Hayden et al. 1990; Rieder and Alexander 1990) and subsequently found in budding yeast and fission yeast (Tanaka et al. 2005a; Franco et al. 2007; Gachet et al. 2008); therefore, this mode of the capture is widely conserved among eukaryotic cells.

Prior to the initial interaction between microtubules and kinetochores, microtubules repeatedly grow and shrink in various directions, thus, in effect searching for kinetochores (Kirschner and Mitchison 1986). However, the initial encounter happens more efficiently than is likely to be explained by a random search-and-capture process (Wollman et al. 2005). In the Xenopus egg extract system, this efficiency might be explained by the presence of a concentration gradient of RanGTP and its associated proteins, around the chromosomes, which facilitates microtubule extension towards chromosomes (CarazoSalas and Karsenti 2003; Caudron et al. 2005). Moreover, in yeast, fly, and vertebrate cells, microtubules extend not only from spindle poles but also from kinetochores (Khodjakov et al. 2003; Maiato et al. 2004b; Rieder 2005; our unpublished data). Such kinetochore-derived microtubules subsequently interact with pole-derived microtubules and seem to help in recruiting kinetochores onto the lattice of pole-derived microtubules, at least in some occasions.

Once bound to the microtubule lattice, kinetochores are transported towards a spindle pole along the microtubule (Fig. 1, step 2, sliding). Poleward kinetochore transport is especially crucial when kinetochores are located far away from the mitotic spindle. Kinetochore sliding along a microtubule is promoted by minus end-directed motor proteins, dynein in vertebrate cells (King et al. 2000; Yang et al. 2007), and Kar3, a kinesin-14 family member, in budding yeast (Tanaka et al. 2005a, 2007). Dynein is a processive, and Kar3 is a nonprocessive motor protein, meaning that the motor-microtubule interaction is maintained or interrupted, respectively, after each ATPase cycle (Endow 2003). This explains the rapid kinetochore sliding (10 $50 \mu \mathrm{m} / \mathrm{min}$ ) in vertebrate cells (Hayden et al. 1990; Rieder and Alexander 1990) and slow/intermittent sliding (1$1.5 \mu \mathrm{m} / \mathrm{min}$ ) in yeast (Tanaka et al. 2005a, 2007). Dynein localizes only outside of nuclei in yeast (Hildebrandt and Hoyt 2000); presumably, upon the evolution of open mitosis, metazoans acquired the ability to use dynein in functions that had previously been exclusively nuclear.

Microtubules still maintain their dynamic nature, growing, and shrinking at their plus ends distal to the spindle pole, even while kinetochores are transported along their lattice (Hayden et al. 1990; Rieder and Alexander 1990; Tanaka et al. 2005a). This may pose a challenge to budding yeast, because the speed of microtubule shrinkage (2.5$3 \mu \mathrm{m} / \mathrm{min}$ ) exceeds the velocity of kinetochore sliding (Tanaka et al. 2005a). Shrinking microtubule plus ends indeed often catch up with sliding kinetochores, which potentially could cause their subsequent release from the plus ends. However, such release hardly ever occurs because, when the microtubule plus ends reach kinetochores, either of the following two options is taken (Tanaka et al. 2007): (1) microtubules show regrowth (rescue) or (2) kinetochores become tethered at microtubule plus ends and continue to be pulled further towards a spindle pole as microtubules shrink (Fig. 1, step 2, end-on pulling). Kinetochore attachment at the microtubule end is more stable than its lattice association (Tanaka et al. 2007), and, therefore, ideal to resist tension when bi-orientation is subsequently established (see "Geometry- and tension-dependent mechanisms promoting bi-orientation" section).

Once kinetochores attach to the microtubule ends, they cannot revert to lateral attachment to the same microtubules (Tanaka et al. 2007). However, when end-on attached kinetochores reach a spindle pole in vertebrate cells, they can slide along the surface of other microtubules that are already attached to bi-oriented kinetochores, while maintaining their original end-on attachment (Kapoor et al. 2006). This sliding takes place away from a spindle pole, driven by the CENP-E motor protein, and 
Step 1. Kinetochore initially interacts with the lateral surface of a microtubule
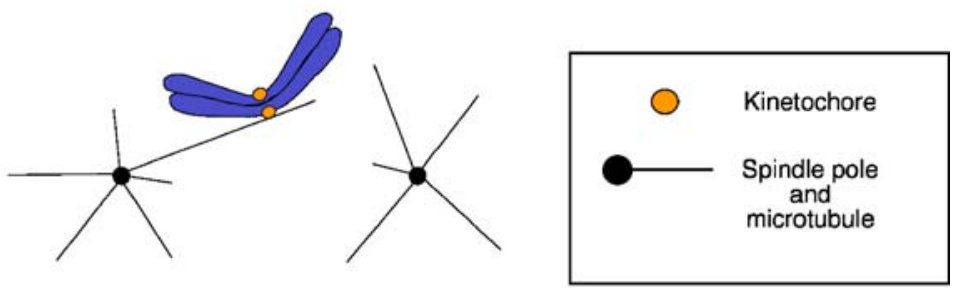

Step 2. Microtubule-dependent kinetochore transport towards a spindle pole Sliding
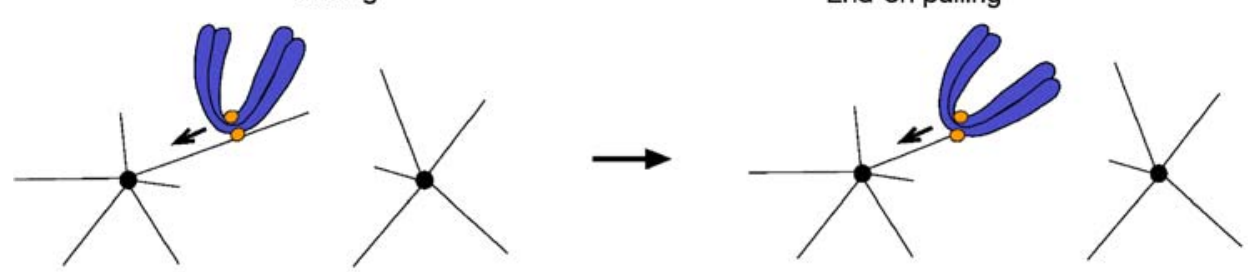

Step 3. Interaction of sister kinetochores with microtubules from the same or opposite spindle poles
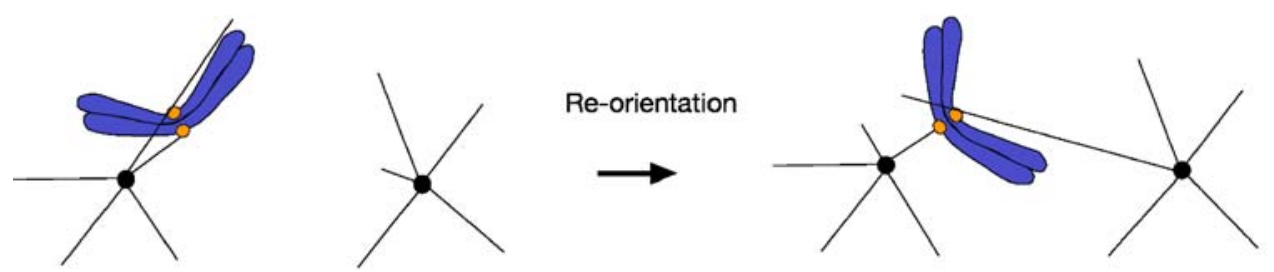

Step 4. Sister kinetochore bi-orientation (tension applied: metaphase)

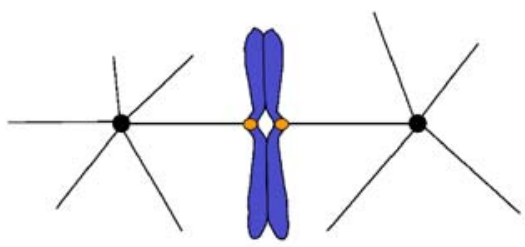

Step 5. Sister chromatid separation (anaphase A)

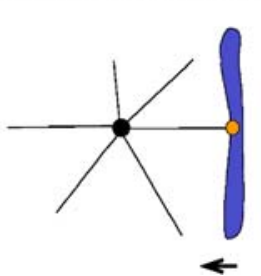

Fig. 1 Overview of kinetochore-microtubule interactions. The figure depicts kinetochore-microtubule interactions during prometaphase (steps 1-3), metaphase (step 4), and anaphase A (step 5). The figure is adapted from figures in Tanaka and Desai (2008) and Tanaka et al. (2005b). (1) Kinetochores initially interact with the lateral surface of single microtubules that extend from one of the spindle poles (Hayden et al. 1990; Rieder and Alexander 1990; Tanaka et al. 2005a). (2) Once captured, kinetochores are transported along the lateral surface of single microtubules toward the spindle pole (sliding; Hayden et al. 1990; Rieder and Alexander 1990; Tanaka et al. 2005a). Subsequently, at least in budding yeast, kinetochores are tethered at the end of the single microtubules and transported further as the microtubules shrink (end-on pulling; Kitamura et al. 2007; Tanaka et al. 2007). (3) As kinetochores approach spindle poles, both sister kinetochores attach to microtubules. If both kinetochores attach to microtubules from the

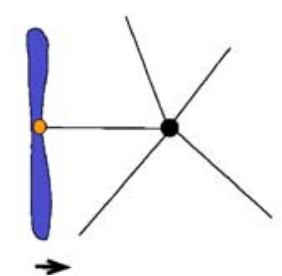

same spindle pole, kinetochore-spindle pole connections by microtubules are re-oriented until proper bi-orientation is established (Nicklas 1997; Tanaka et al. 2005b). (4) Cessation of re-orientation is dependent on the tension that is generated by microtubules upon establishment of bi-orientation (Nicklas 1997; Tanaka et al. 2005b). The number of microtubules whose plus ends attach to a single kinetochore increases when tension is applied in metazoan cells (King and Nicklas 2000), while only a single microtubule is thought to attach to each kinetochore in budding yeast (Winey et al. 1995; the latter case is shown here for simplicity). (5) Once all kinetochores biorient on the spindle, cohesion between sister chromatids is removed, causing sister chromatid segregation to opposite spindle poles during anaphase A (Nasmyth 2002). Kinetochores are end-coupled and pulled poleward as the microtubules depolymerize (Rogers et al. 2005; Kwok and Kapoor 2007) 
helps kinetochores to align in the middle of the metaphase spindle.

\section{Interface of kinetochore microtubule interaction: the Ndc80 and Dam1 complexes}

Kinetochores are large protein complexes, consisting of dozens of protein components (reviewed in Cleveland et al. 2003; Maiato et al. 2004a; Westermann et al. 2007; Cheeseman and Desai 2008). Among them, which components make a direct contact with microtubules? Recent studies have revealed that two components, the $\mathrm{Ndc} 80$ and Dam1 complexes, play central roles in making this contact.

The Ndc80 complex is an outer kinetochore component, structurally conserved from yeast to vertebrates, and the depletion or inactivation of this complex causes severe defects in kinetochores-microtubule interaction (reviewed in Ciferri et al. 2007; Cheeseman and Desai 2008). The $\mathrm{Ndc} 80$ complex is composed of four proteins: $\mathrm{Ndc} 80$ (also called Hec1 in mammals), Nuf2, Spc24, and Spc25 (Fig. 2a). Ndc80-Nuf2 and Spc24-Spc25 form heterodimers with a globular domain at the end of a coiled-coil shaft (Ciferri et al. 2005; Wei et al. 2005; Wei et al. 2006). The two heterodimers are held together by interaction of their coiled-coil shafts, making a heterotetramic rod structure with globular domains at both ends. The Spc24Spc25 globular domain is oriented towards the inner kinetochore and the rod structure projects outwards to microtubules (DeLuca et al. 2006).

Importantly, recent biochemical analyses and electron microscopy showed that the Ndc80-Nuf2 globular domain directly interacts with the microtubule lattice, without showing preference for microtubule ends (Fig. 2a; Cheeseman et al. 2006; Wei et al. 2007). Consistent with this, the Ndc80 complex has a crucial role in kinetochore association with the microtubule lattice in vivo in budding yeast (Fig. 1, step 1; Tanaka et al. 2005a). The crystal structure of the Ndc80-Nuf2 globular domain revealed that each of the Ndc80 and Nuf2 polypeptides is folded as a calponin homology (CH) domain (Wei et al. 2007; Ciferri et al. 2008). Positively charged residues in the $\mathrm{CH}$ domains are important for microtubule lattice binding (Ciferri et al. 2008). Another microtubule-associated protein EB1 also folds as a $\mathrm{CH}$ domain (Hayashi and Ikura 2003), which is, therefore, a commonly used structure for microtubule association. In $\mathrm{Ndc} 80$, an unstructured N-terminal 80- to 100-residue basic region protrudes from the $\mathrm{CH}$ domain and phosphorylation of this peptide by Aurora B kinase has a crucial role in regulating kinetochores-microtubule interaction (Cheeseman et al. 2006; DeLuca et al. 2006; Ciferri et al. 2008; see "Regulators promoting bi-orientation: Aurora B/Ipl1 kinase and more" section).
The Ndc80 complex is associated with other kinetochore components, KNL1 (Spc105/Spc7 budding and fission yeast, respectively), and the Mis 12 complex (Liu et al. 2005; Cheeseman et al. 2006). This interacting protein set, called the KMN network, shows higher affinity for microtubules than the Ndc80 complex alone (Cheeseman et al. 2006). In particular, KNL1 seems to make an additional microtubule-binding interface (Cheeseman et al. 2006; Kiyomitsu et al. 2007).

As discussed above, kinetochores initially interact with the microtubule lattice and subsequently attach to the plus ends of microtubules. To maintain kinetochore association with dynamic microtubule plus ends, which molecules are involved in their interface? In yeast cells, the Dam1 complex has a crucial role in this process. The Dam1 complex, also called DASH or DDD, is composed of ten proteins and has been identified in budding and fission yeasts (reviewed in Westermann et al. 2007). The Dam1 complex locates along microtubules, but not at kinetochores during their microtubule lattice association (Kitamura et al. 2007; Tanaka et al. 2007). Subsequently this complex is loaded onto kinetochores and plays an important role, perhaps in association with the Ndc80 complex, in tethering them at microtubule plus ends (Janke et al. 2002; Shang et al. 2003; Wong et al. 2007) as well as in pulling them poleward as microtubules depolymerize (Fig. 1, step 2, end-on pulling; Fig. 2b; Franco et al. 2007; Tanaka et al. 2007; Gachet et al. 2008). Biochemical reconstitution revealed that about 16 Dam1 complexes oligomerize and form a ring that encircles a microtubule (Fig. 2b; Miranda et al. 2005; Westermann et al. 2005; Wang et al. 2007). Separate studies suggest that the Dam1 complex can also be present on a microtubule without

Fig. 2 The Ndc80 complex and the Dam1 complex. a The Ndc80 complex. Diagram shows four components and defined domains of the complex (top, left). Rotary shadowing electron micrographs show rod-like structure of the complex (top, right; scale bar $100 \mathrm{~nm}$; reprinted from Wei et al. 2005, with permission; Copyright (C) 2005 The National Academy of Sciences of the USA). Negatively stained microtubules in the presence (bottom right) and absence (bottom left) of the Ndc80 complex (reprinted from Cheeseman et al. 2006, with permission; Copyright (C) 2006 Elsevier). The Ndc80 complex forms angled rod-like projections on the microtubule lattice. b The Dam1 complex. The Dam1 complexes are present in vitro as a ring encircling a microtubule (Miranda et al. 2005; Westermann et al. 2005; Wang et al. 2007) but also as an oligomer that does not form a ring (Gestaut et al. 2008; Grishchuk et al. 2008). Both forms could accumulate at the microtubule plus end during the outward curling of protofilaments that accompanies depolymerization (top, left); this accumulation was observed in vitro (Westermann et al. 2006; Gestaut et al. 2008; Grishchuk et al. 2008) and in vivo (Tanaka et al. 2007). The Dam1 complex has a crucial role in tethering kinetochores at microtubule ends and in converting microtubule depolymerization into kinetochore pulling force (top, right; Asbury et al. 2006; Westermann et al. 2006; Tanaka et al. 2007). Electron micrographs of negatively stained microtubules in the presence of the Dam1 complexes (bottom, scale bar $50 \mathrm{~nm}$; reprinted from Miranda et al. 2005, with permission; Copyright (C) 2005 Nature Publishing Group) 

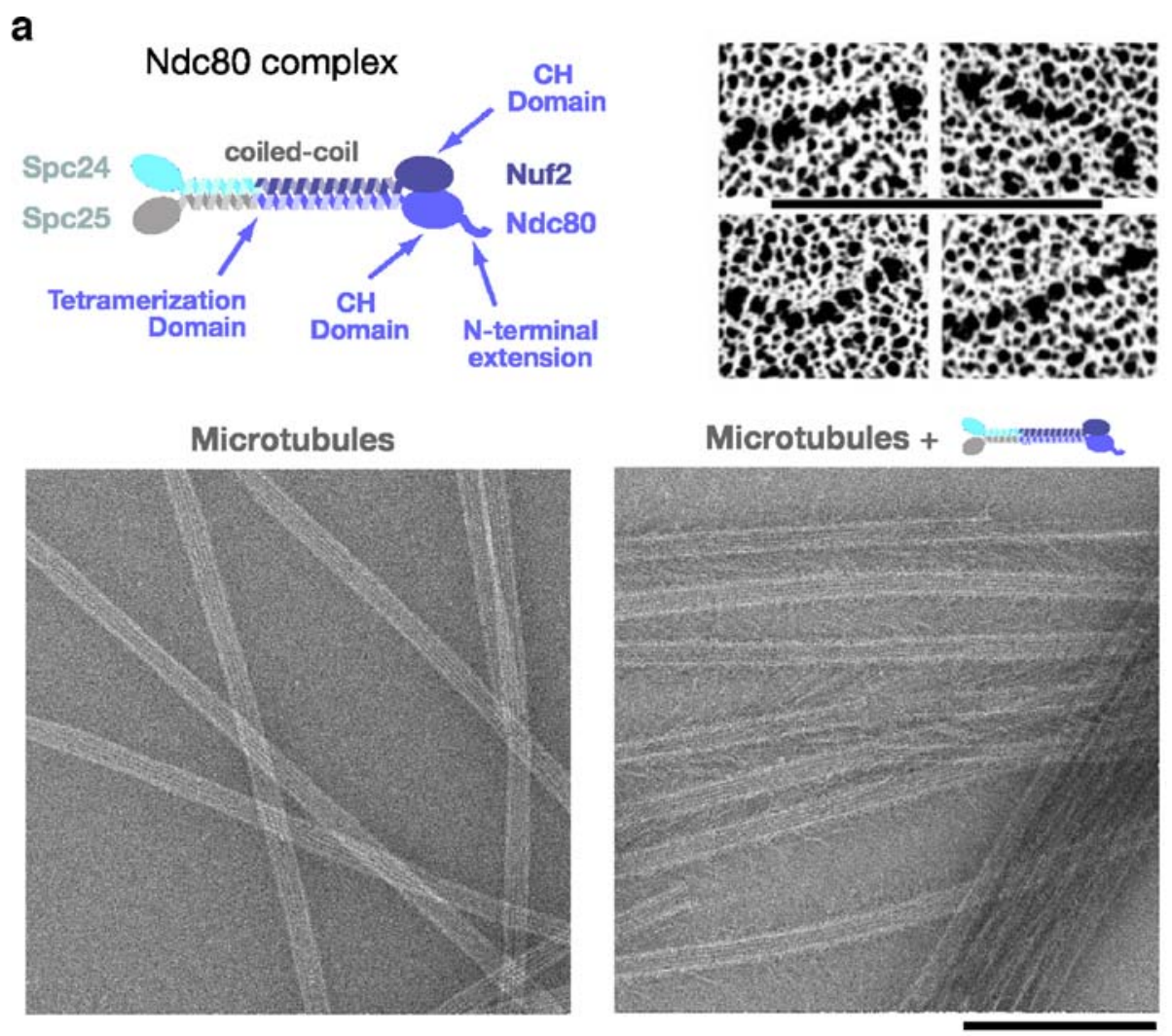

b

\section{Dam1 complex}

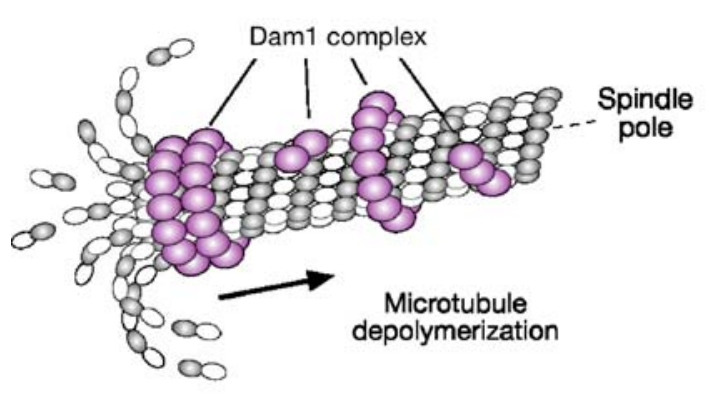

\section{End-on pulling}
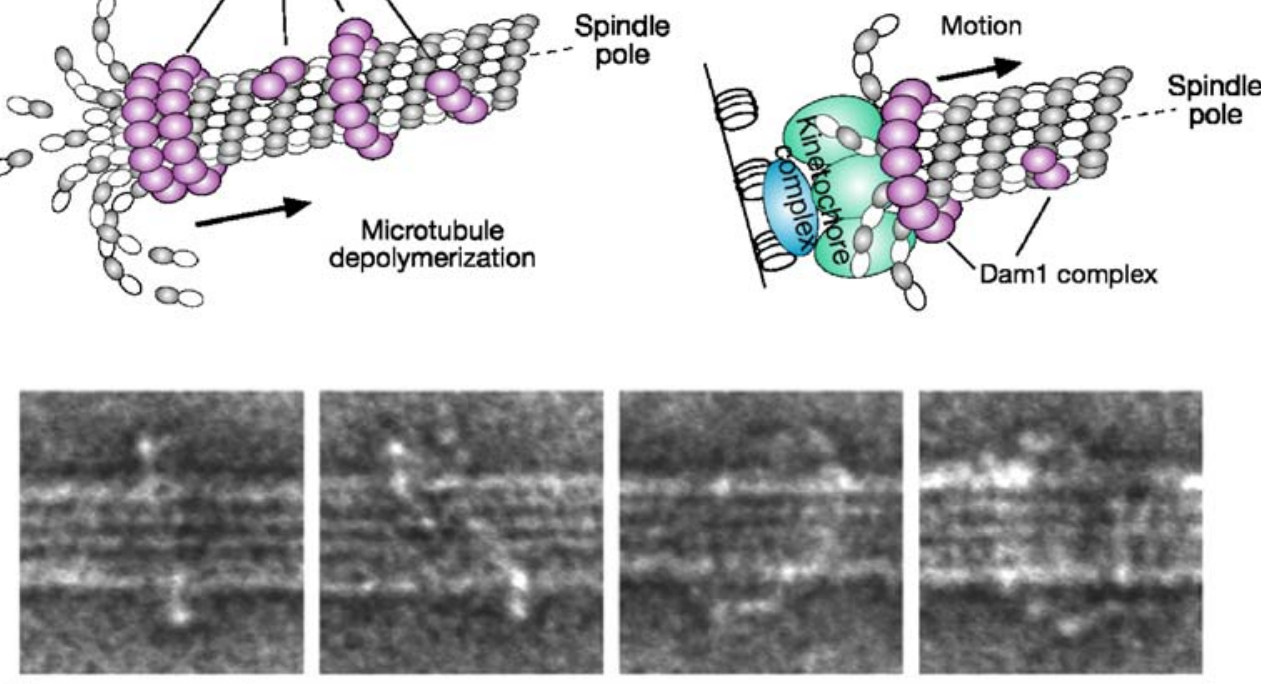

forming a ring (Gestaut et al. 2008; Grishchuk et al. 2008). Both forms can track and accumulate at the plus ends of depolymerizing microtubules in vitro (Asbury et al. 2006; Westermann et al. 2006; Gestaut et al. 2008; Grishchuk et al. 2008), as the Dam1 complex indeed does so in vivo (Tanaka et al. 2007), though whether as rings, independent complexes or both is not yet known.
During microtubule depolymerization, protofilaments splay out at the plus ends. In vitro reconstitution and mathematical models suggest that such protofilament curling produces a force sufficient to move chromosomes towards spindle pole (Grishchuk et al. 2005; Liu and Onuchic 2006; Efremov et al. 2007). It is suggested that the Dam1 complex is required to convert microtubule depoly- 
merization to a kinetochore pulling force (Asbury et al. 2006; Westermann et al. 2006; Tanaka et al. 2007). In particular, if the Dam1 complex forms a ring in vivo as well as in vitro, such a ring (whose inner diameter is slightly larger than the microtubule diameter; Miranda et al. 2005; Westermann et al. 2005; Wang et al. 2007) will be pushed poleward by protofilament curling, making an ideal device for end-on pulling of kinetochores (Fig. 2b). This function of the Dam1 complex is important for chromosome motion in prometaphase (Fig. 1, step 2, end-on pulling; Kitamura et al. 2007; Tanaka et al. 2007); presumably, the complex plays a similar role in anaphase A, where kinetochores move towards a spindle pole again by microtubule end-on pulling (Fig. 1, step 5). In addition, the complex may also play a role in tension-coupled chromosome oscillation during metaphase, as suggested by an in vitro reconstitution study (Franck et al. 2007).

Although the Dam1 complex has essential roles in kinetochore association with the end of microtubules in budding yeast, convincing orthologs of Dam1 components have not been identified in metazoa (Meraldi et al. 2006). How can this be reconciled? One possibility is that functional counterparts of the Dam1 complex exist in metazoa, albeit with little homology in amino acid sequences; Ska1/2, Cep57, and Bod1 are such candidates (Hanisch et al. 2006; Emanuele and Stukenberg 2007; Porter and Swedlow 2007), although their functional similarity to the Dam1 complex must be studied further. Alternatively, the role of the Dam1 complex may be more important in organisms such as budding yeast, in which a single kinetochore attaches to a single microtubule in metaphase (Winey et al. 1995). Thus, functional counterparts of the Dam1 complex may not be required in metazoan cells, which have several microtubules per kinetochore and in which components such as the KMN network (see above) may be sufficient for kinetochore association with the ends of the majority of microtubules, even if some microtubules may detach. Consistent with this notion, fission yeast (but not budding yeast), where twofour microtubules attach to a single kinetochore (Ding et al. 1993), can still proliferate in the absence of the Dam1 complex, albeit with frequent chromosome missegregation (Liu et al. 2005; Sanchez-Perez et al. 2005). Requirement of the Dam1 complex, and any possible counterparts, for cell proliferation may be also correlated with their ability to form a ring encircling a microtubule (see above). Intriguingly, budding yeast has a sufficient number of the Dam1 complexes to form a ring at each kinetochore microtubule (Joglekar et al. 2006), but fission yeast has fewer (Joglekar et al. 2008). Electron tomography of vertebrate cells also suggested that microtubule ends are embedded in a fibrous network rather than in ring structures, within kinetochore outer plates in metaphase (Dong et al. 2007).

\section{Geometry- and tension-dependent mechanisms promoting bi-orientation}

After kinetochores are transported polewards (Fig. 1, step 2), each sister kinetochore eventually attaches to microtubules that extend from opposite spindle poles (biorientation; Fig. 1, step 4). To achieve bi-orientation, wrong orientations of kinetochore microtubule attachment, e.g., sister kinetochores attaching to microtubules from the same spindle pole (syntelic attachment; Fig. 3), must be either avoided or corrected before anaphase onset. It has been thought that two kinds of mechanism could promote this process - a geometry-dependent mechanism and a tensiondependent mechanism (Ault and Rieder 1992; Tanaka et al. 2005b).
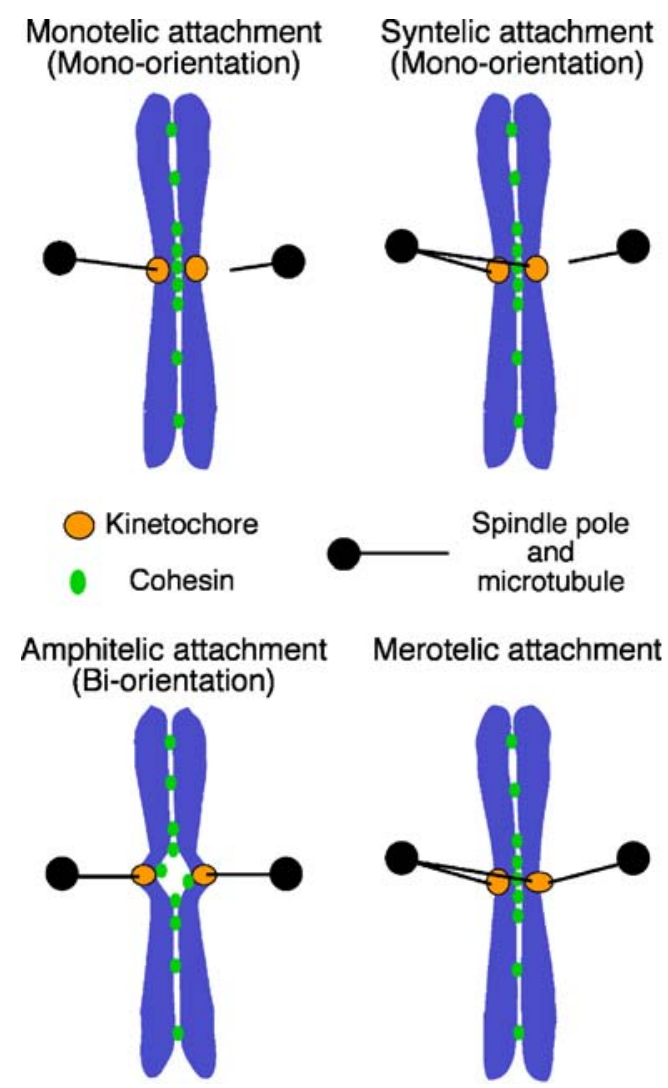

Fig. 3 Modes of kinetochore-microtubule interactions. Monotelic attachment - one of the sister kinetochores attaches to microtubules whereas the other does not attach to any microtubules. Syntelic attachment - both sister kinetochores attach to microtubules extending from one spindle pole. As a results of monotelic or syntelic attachment, sister kinetochores "mono-orient"; that is, they are connected to only one spindle pole directly or indirectly. Amphitelic attachment - each sister kinetochore attaches to microtubules extending from opposite spindle poles. As a result of amphitelic attachment, sister kinetochores "bi-orient"; that is, they are connected to the opposite spindle poles. Merotelic attachment-one sister kinetochore simultaneously attaches to microtubules extending from both spindle poles. The figure is adapted from a figure in Tanaka et al. (2005b) 
The geometry-dependent mechanism relies on a back-toback position of sister kinetochores mainly due to cohesion between sister centromeres. When one kinetochore attaches to microtubules from one spindle pole (monotelic attachment; Fig. 3), the constraint in geometry makes the other face the opposite direction, allowing association with microtubules only from the opposite pole. Thus, wrong orientations of kinetochore-microtubule attachment would be discouraged by this mechanism. However, if wrong orientations are formed, the geometry mechanism can no longer correct them.

By contrast, the tension mechanism is important in correcting wrong orientation of kinetochore-microtubule attachment, relying on tension applied on this attachment (Ault and Rieder 1992; Tanaka et al. 2005b). Such error correction was first discovered in meiosis I, where two homologous kinetochores must bi-orient on the spindle. They are connected via chiasmata and able to change their geometry flexibly. Here, kinetochores and spindle poles are repeatedly connected and disconnected by microtubules until bi-orientation is established (Nicklas 1997). Using microneedle manipulation in grasshopper spermatocytes, Nicklas and colleague showed that tension applied on chromosomes leads to stabilization of kinetochore-spindle pole connections (Nicklas and Koch 1969; Nicklas 1997).

In contrast to meiosis I, both geometry- and tensionmechanisms may work in mitosis; however, the relative contribution of the two mechanisms in promoting biorientation in mitosis has been an issue of debate (Ault and Rieder 1992). To address this issue, an unreplicated circular minichromosome with two centromeres was engineered and its behavior was observed in budding yeast (Dewar et al. 2004). On this minichromosome, two centromeres would lack back-to-back geometry as they are not sisters born by DNA replication, but tension should be generated across them by intercentromere chromatin, if two centromeres bi-orient on the spindle. Such a minichromosome always and efficiently bi-oriented, suggesting that tension across its two kinetochores is sufficient to promote bi-orientation (Dewar et al. 2004). The corollary of this observation is that in normal sister chromatids, kinetochore-spindle pole connections change their orientation repeatedly until, upon bi-orientation, cohesion between sister kinetochores provides resistance and consequently tension, which stabilizes the connections (Fig. 1, steps 3-4).

However, the above observation does not exclude a redundant role for geometry in facilitating bi-orientation in mitosis (Indjeian and Murray 2007). Cohesion between sister kinetochores is thought to be important for sister kinetochore geometry. Thus, it is likely that cohesion has important roles in both geometry- and tension-dependent mechanisms for bi-orientation. Cohesins are required for sister chromatid cohesion (Nasmyth 2002) and their depletion indeed leads to extensive defects in bi-orientation (Tanaka et al. 2000; Sonoda et al. 2001; Dewar et al. 2004; Vagnarelli et al. 2004). In particular, recent studies characterized the relevant role of cohesins at pericentric regions in yeast (Eckert et al. 2007; Ocampo-Hafalla et al. 2007; Yeh et al. 2008). The geometry of sister kinetochores may also be facilitated by their nature such that, once forming a particular geometry, they 'memorize' and tend to maintain such geometry (Loncarek et al. 2007). However, after syntelic attachment is sustained for some time, sister kinetochores remain juxtaposed due to this nature and in order to restore their back-to-back geometry, microtubules must pull them towards opposite spindle poles (Loncarek et al. 2007).

In contrast to budding yeast, multiple microtubules attach to a single kinetochore in fission yeast and metazoan cells (McDonald et al. 1992; Ding et al. 1993). In this situation, errors could happen in such a way that a single kinetochore becomes attached to microtubules from the opposite spindle poles (merotelic attachment; Fig. 3). How do cells avoid and/or correct this type of errors? Merotelic attachments are probably discouraged by geometry-dependent mechanisms. For example, the Psc1/Mde4 complex is a proposed clamp to ensure this geometry in fission yeast kinetochores (Gregan et al. 2007). However, if merotelic attachments are unavoidably formed, some of them still seem to be corrected prior to anaphase onset (see "Regulators promoting bi-orientation: Aurora B/Ipl1 kinase and more" section; Cimini et al. 2003; Cimini et al. 2006). Even if merotelic attachments remain until anaphase, the imbalance between forces applied on sister kinetochores often results in their proper segregation (Cimini et al. 2004).

\section{Regulators promoting bi-orientation: Aurora B/Ipl1 kinase and more}

In addition to proteins necessary for the kinetochorespindle pole connections by microtubules and for sister chromatid cohesion, what factors are required to promote sister kinetochore bi-orientation? Aurora B (called Ipl1 in budding yeast) is an evolutionarily conserved serine/ threonine protein kinase and has essential roles in promoting bi-orientation (reviewed in Tanaka et al. 2005b; Ruchaud et al. 2007). In fact, inhibition or mutants of Aurora B/Ipl1 show extensive chromosome missegregation in metazoan and yeast cells.

In ipll mutants, the kinetochore-spindle pole connections are present but their orientation is specifically defective (Biggins and Murray 2001; He et al. 2001; Tanaka et al. 2002). In the ipll mutant, an unreplicated circular minichromosome with two centromeres (see above) often failed to bi-orient, suggesting that Ipl1 could facilitate bi-orientation by a tension-dependent mechanism (Dewar 
et al. 2004). Moreover, in this mutant, centromeres failed to change their spindle pole association in the absence of tension (Tanaka et al. 2002; Dewar et al. 2004). It was therefore suggested that Ipl1 kinase promotes turnover of kinetochore-spindle pole microtubule connections and eliminates those that do not generate tension between sister kinetochores (Fig. 4). Aurora B has a similar role in mammalian cells, as they accumulate syntelic kinetochoremicrotubule attachments when this kinase is inhibited (Hauf et al. 2003; Lampson et al. 2004).

Aurora B/Ipl1 localizes at kinetochores in prometaphse and metaphase and seems to promote turnover of kinetochore-microtubules attachments by phosphorylating kinetochore components. Crucial substrates include the Dam1 complex in budding yeast (Cheeseman et al. 2002; Zhang et al. 2005) and the Ndc80 complex (Cheeseman et al. 2006; DeLuca et al. 2006; Ciferri et al. 2008) and MCAK (Andrews et al. 2004; Lan et al. 2004; Ohi et al. 2004; Knowlton et al. 2006; Zhang et al. 2007) in mammalian cells. Phosphorylation of Dam1 is clustered at its C terminus and this region is important for ring formation and microtubule interaction of the Dam1 complex in vitro (Cheeseman et al. 2002; Wang et al. 2007). On the other hand, phosphorylation of $\mathrm{Ndc} 80$ is clustered at its $\mathrm{N}$ -

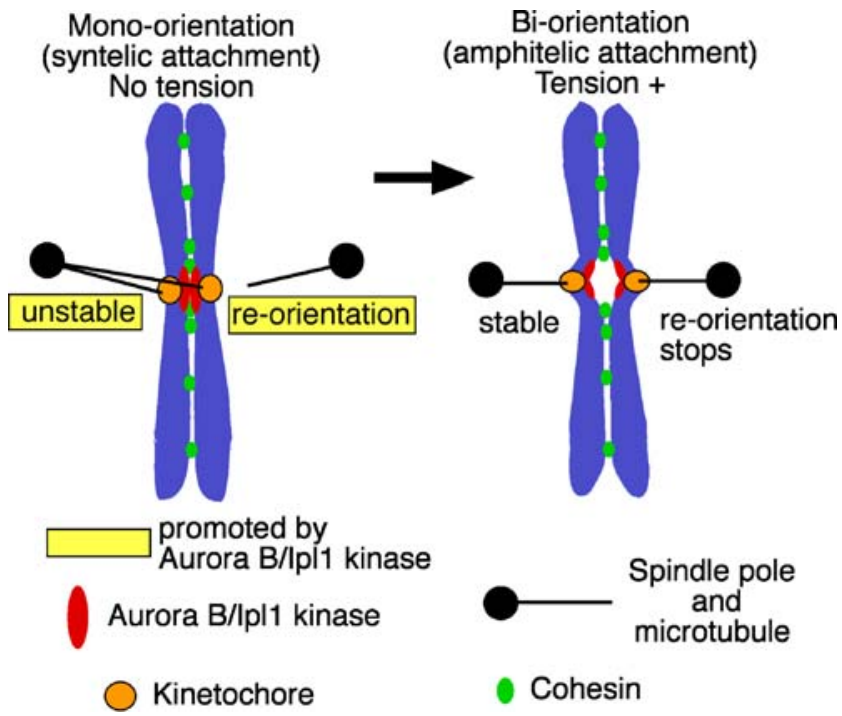

Fig. 4 How Aurora B/Ipl1 facilitates sister kinetochore bi-orientation. The Aurora B/Ipl1 kinase facilitates bi-orientation by promoting the re-orientation of kinetochore-spindle pole connections in a tensiondependent manner (Tanaka et al. 2002; Dewar et al. 2004). Because syntelic attachment does not generate tension on kinetochore-to-pole connections, Aurora B/Ipl1 promotes re-orientation of these connections (by phosphorylating kinetochore components; see main text). When an amphitelic attachment is established, tension is applied on kinetochore-to-pole connections, and as a result, Aurora B/Ipl1 stops promoting their re-orientation, which causes preferential selection of the amphitelic attachment. The figure is adapted from a figure in Tanaka et al. (2005b) terminal basic region and reduces affinity of the $\mathrm{Ndc} 80$ complex for microtubules in vitro (Cheeseman et al. 2006; Ciferri et al. 2008). Moreover, daml and ndc 80 mutants mimicking constitutive dephosphorylation show defects in bi-orientation in vivo (Cheeseman et al. 2002; DeLuca et al. 2006). Furthermore, the microtubule depolymerizing activity of MCAK, regulated by Aurora B, might be important to remove syntelic and merotelic attachments (Andrews et al. 2004; Lan et al. 2004; Ohi et al. 2004; Knowlton et al. 2006; Zhang et al. 2007).

In metazoan cells where multiple microtubules attach to a single kinetochore, Aurora B may have a more complex role in promoting bi-orientation. For example, inhibition of Aurora B leads to not only syntelic attachment but also merotelic attachment (Cimini et al. 2006; Knowlton et al. 2006; see "Geometry- and tension-dependent mechanisms promoting bi-orientation" section). Aurora B (together with Polo kinase) also promotes resolution of sister chromatids (Losada et al. 2002), which may facilitate bi-orientation, in addition to turnover of kinetochore-microtubule attachment promoted by this kinase.

Aurora B/Ipl1 kinases are also known as 'passenger proteins' as they relocate from kinetochores to the spindle upon anaphase onset (Ruchaud et al. 2007). This relocation, regulated by $\mathrm{Cdc} 14$ phosphatase in yeast (Pereira and Schiebel 2003) and cyclin B destruction in fly (Parry et al. 2003), is probably important to stop the turnover of kinetochore-spindle pole connections during anaphase, when tension on kinetochores is much reduced. In fact, when this relocation of Aurora B/Ipl1 is inhibited, kinetochores do continuously re-orient on the anaphase spindle (Parry et al. 2003).

Mps1 is another evolutionarily conserved protein kinase, which is required for the spindle assembly checkpoint and, in some organisms, for duplication of MTOCs of the mitotic spindle (reviewed in Winey and Huneycutt 2002). Separately from these functions, however, Mps1 has an important role in chromosome segregation, especially in sister kinetochore bi-orientation (Jones et al. 2005; Maure et al. 2007). Similarly to Aurora B/Ipl1, Mps1 promotes turnover of kinetochore-microtubule attachment that does not generate tension (Maure et al. 2007). In humans, Mps1 regulates Aurora B kinase activity by phosphorylating Borealin (also called Dasra B) that binds Aurora B (Jelluma et al. 2008); this explains the role of Mps1 as an upstream regulator of Aurora B. Budding yeast, however, does not have an ortholog of Borealin, and Mps1 and Ipl1 may work in a parallel pathway (Maure et al. 2007).

Once bi-orientation is established and tension is applied on kinetochores, turnover of kinetochore-spindle pole connections must stop (Pearson et al. 2004; Tanaka et al. 2005b); otherwise, bi-orientation would never be maintained. For this, sensing tension is of central importance, 
but which component works as a tension sensor? Bir1 and Sli15 (Survivin and INCENP in metazoa) are binding partners of Ipl1 in yeast and regulate its kinase activity (reviewed in Ruchaud et al. 2007). Bir1 and Sli15 form a subcomplex bridging between a microtubule and a kinetochore and, thus, ideally positioned to sense tension (Sandall et al. 2006); they may regulate Ipl1 activity accordingly although this remains to be demonstrated. On the other hand, in the Xenopus egg extract system, the kinase activity of Aurora B, locating at inner centromeres, may be enhanced by proximity to microtubules, only during syntelic and merotelic attachment (Ohi et al. 2003; Rosasco-Nitcher et al. 2008). In mammals, another candidate for a tension sensor might be $\mathrm{PICH}$, a Snf2 family member, which shows a unique thread-like localization between bi-oriented sister kinetochores (Baumann et al. 2007). In an alternative model, when tension is applied, kinetochore substrates may be sequestered from Aurora B that locates at inner centromeres in animal cells; this may lead to dephosphorylation of kinetochore substrates (Tanaka et al. 2002; Andrews et al. 2004). However, in budding yeast, such a delocalization between kinetochores and Ipll may not be easily observed due to resolution constraints (Buvelot et al. 2003; Tanaka et al. 2005b).

Bubl and Sgo proteins (Sgol in budding yeast and Sgo2 in fission yeast) are required to ensure bi-orientation in yeast (Asakawa et al. 2005; Fernius and Hardwick 2007; Kawashima et al. 2007; Vanoosthuyse et al. 2007) and in mammals (Meraldi and Sorger 2005). Nonetheless, in their absence, yeast cells are still able to proliferate, albeit with increased rates of chromosome missegregation, suggesting a role for them in "fine tuning" of biorientation (contrasting with the essential roles of Aurora $\mathrm{B} / \mathrm{Ip} 11$ and Mps1 kinases). It is suggested that Bub1 is required for Sgo recruitment at kinetochores, which in turn contributes to full-scale Aurora B loading there (Fernius and Hardwick 2007; Kawashima et al. 2007; Vanoosthuyse et al. 2007).

\section{Bi-orientation and spindle assembly checkpoint: convoluted relation}

The spindle assembly checkpoint is a surveillance mechanism that delays anaphase onset if kinetochores fail to attach to microtubules, or if sister kinetcohores fail to biorient on the spindle (reviewed in Musacchio and Salmon 2007; Burke and Stukenberg 2008). Such failure is sensed at kinetochores, signals via Mad and Bub proteins and eventually inhibits $\mathrm{Cdc} 20$, an activator of the anaphasepromoting complex. The spindle assembly checkpoint is distinct from the bi-orientation-promoting mechanisms discussed above ("Geometry- and tension-dependent mech- anisms promoting bi-orientation" and "Regulators promoting bi-orientation: Aurora B/Ipl1 kinase and more" sections); the former one does not promote bi-orientation by itself but rather earns time for the latter one to promote bi-orientation. Moreover, in yeast, the spindle assembly checkpoint is not required for proper chromosome segregation during normal, undisturbed cell cycles (Warren et al. 2002), in contrast to mechanisms promoting bi-orientation. This suggests that yeast cells normally have enough time to establish bi-orientation without relying on checkpointdependent delay of anaphase onset. By contrast, in mammals, the spindle assembly checkpoint is crucial for proper chromosome segregation even during normal cell cycles (e.g., Dobles et al. 2000). Nonetheless, in mammals, defects in the checkpoint can be distinguished from defects in bi-orientation-promoting mechanisms as follows: when metaphase is prolonged, for example, using a proteasome inhibitor, bi-orientation is restored in cells with a checkpoint defect, but not in cells with a defect in bi-orientationpromoting mechanisms (e.g., Jelluma et al. 2008).

Although the two mechanisms are clearly distinct, they cooperate with each other to establish bi-orientation; checkpoint buys time for bi-orientation-promoting mechanisms to work. However, their cooperation is not unilateral. In some cases, due to bi-orientation-promoting mechanisms, the spindle assembly checkpoint remains active. For example, when no tension is applied on kinetochores, Aurora B/Ipl1 promotes turnover of kinetochore-microtubule attachment, thus, generating unattached kinetochores which keeps the checkpoint active (Tanaka et al. 2002; Hauf et al. 2003; Pinsky et al. 2006). Mps1 and Sgo may be involved in maintaining checkpoint activity by a similar mechanism in the absence of tension on kinetochores (Dorer et al. 2005; Indjeian et al. 2005). Thus, defects in bi-orientation are sensed by the checkpoint, partly through generation of unattached kinetochores.

However, independently of this process, an active spindle assembly checkpoint seems to require Aurora B/Ipl1 (Ditchfield et al. 2003; Morrow et al. 2005; King et al. 2007) and Mps1 kinases (see below). For example, when tension is not applied on kinetochores, Mad3 phosphorylation by Ipl1 becomes essential for checkpoint activity, but not for establishment of bi-orientation (therefore, presumably, not for turnover of kinetochore-microtubule attachment; King et al. 2007). Moreover, when kinetochores fail to attach to microtubules (e.g., when microtubules are depolymerized by nocodazole), Mps1 is crucial for activating the checkpoint even if there is no kinetochore-microtubule attachment to be turned over (Weiss and Winey 1996). Thus, the spindle assembly checkpoint and mechanisms promoting bi-orientation are related in a convoluted way, which ensures their close cooperation to achieve bi-orientation. 


\section{Conclusions and perspectives}

Establishing sister kinetochore bi-orientation is a pivotal process for ensuring equal segregation of the genetic information into daughter cells upon cell division. To understand this process, many pertinent questions remain to be answered. For example, how do kinetochores and microtubules efficiently encounter each other and what are the roles of RanGTP gradients, kinetochore-derived microtubules and other factors in this process? How is the kinetochore-microtubule interaction converted from lateral to end-on and how are kinetochores associated with the end of dynamic microtubules; in particular, how are possible Dam1-like-regulators in metazoa and the KMN network involved in this process? How are the merotelic attachments corrected to proper bi-orientation? How does phosphorylation of kinetochore components by Aurora B/Ipl1 facilitate turnover of kinetochore-spindle pole connection? How is the tension on this connection sensed, leading to cessation of this turnover accordingly? How is the bi-orientation-promoting mechanism interlinked with the spindle assembly checkpoint, in particular, do they share tension-sensing mechanisms while using different outputs? The combined efforts in biochemical reconstitution, structural study, genetics, and cell biology will be necessary to advance research in this field.

Acknowledgement The author thanks Lesley Clayton for the helpful comments on the manuscript and Arshad Desai and Stephen Harrison for the high resolution images of figures. Work in the author's lab has been supported by the funding from Cancer Research UK, the Wellcome Trust, Human Frontier Science Program, Lister Research Institute Prize, Association for International Cancer Research and Medical Research Council. The author is a senior research fellow of Cancer Research UK.

Open Access This article is distributed under the terms of the Creative Commons Attribution Noncommercial License which permits any noncommercial use, distribution, and reproduction in any medium, provided the original author(s) and source are credited.

\section{References}

Andrews PD, Ovechkina Y, Morrice N, Wagenbach M, Duncan K, Wordeman L, Swedlow JR (2004) Aurora B regulates MCAK at the mitotic centromere. Dev Cell 6:253-268

Asakawa K, Toya M, Sato M, Kanai M, Kume K, Goshima T, Garcia MA, Hirata D, Toda T (2005) Mal3, the fission yeast EB1 homologue, cooperates with Bub1 spindle checkpoint to prevent monopolar attachment. EMBO Rep 6:1194-1200

Asbury CL, Gestaut DR, Powers AF, Franck AD, Davis TN (2006) The Dam1 kinetochore complex harnesses microtubule dynamics to produce force and movement. Proc Natl Acad Sci U S A 103:9873-9878
Ault JG, Rieder CL (1992) Chromosome mal-orientation and reorientation during mitosis. Cell Motil Cytoskelet 22:155-159

Azimzadeh J, Bornens M (2007) Structure and duplication of the centrosome. J Cell Sci 120:2139-2142

Baumann C, Korner R, Hofmann K, Nigg EA (2007) PICH, a centromere-associated SNF2 family ATPase, is regulated by Plk1 and required for the spindle checkpoint. Cell 128:101-114

Biggins S, Murray AW (2001) The budding yeast protein kinase Ipl1/ Aurora allows the absence of tension to activate the spindle checkpoint. Genes Dev 15:3118-3129

Burke DJ, Stukenberg PT (2008) Linking kinetochore-microtubule binding to the spindle checkpoint. Dev Cell 14:474-479

Buvelot S, Tatsutani SY, Vermaak D, Biggins S (2003) The budding yeast Ipl1/Aurora protein kinase regulates mitotic spindle disassembly. J Cell Biol 160:329-339

Carazo-Salas RE, Karsenti E (2003) Long-range communication between chromatin and microtubules in Xenopus egg extracts. Curr Biol 13:1728-1733

Caudron M, Bunt G, Bastiaens P, Karsenti E (2005) Spatial coordination of spindle assembly by chromosome-mediated signaling gradients. Science 309:1373-1376

Cheeseman IM, Desai A (2008) Molecular architecture of the kinetochore-microtubule interface. Nat Rev Mol Cell Biol 9:33-46

Cheeseman IM, Anderson S, Jwa M, Green EM, Kang J, Yates JR 3rd, Chan CS, Drubin DG, Barnes G (2002) Phospho-regulation of kinetochore-microtubule attachments by the Aurora kinase Ipl1p. Cell 111:163-172

Cheeseman IM, Chappie JS, Wilson-Kubalek EM, Desai A (2006) The conserved KMN network constitutes the core microtubulebinding site of the kinetochore. Cell 127:983-997

Ciferri C, De Luca J, Monzani S, Ferrari KJ, Ristic D, Wyman C, Stark H, Kilmartin J, Salmon ED, Musacchio A (2005) Architecture of the human ndc80-hec1 complex, a critical constituent of the outer kinetochore. J Biol Chem 280:29088-29095

Ciferri C, Musacchio A, Petrovic A (2007) The Ndc80 complex: hub of kinetochore activity. FEBS Lett 581:2862-2869

Ciferri C, Pasqualato S, Screpanti E, Varetti G, Santaguida S, Dos Reis G, Maiolica A, Polka J, De Luca JG, De Wulf P, Salek M, Rappsilber J, Moores CA, Salmon ED, Musacchio A (2008) Implications for kinetochore-microtubule attachment from the structure of an engineered Ndc80 complex. Cell 133:427-439

Cimini D, Moree B, Canman JC, Salmon ED (2003) Merotelic kinetochore orientation occurs frequently during early mitosis in mammalian tissue cells and error correction is achieved by two different mechanisms. J Cell Sci 116:4213-4225

Cimini D, Cameron LA, Salmon ED (2004) Anaphase spindle mechanics prevent mis-segregation of merotelically oriented chromosomes. Curr Biol 14:2149-2155

Cimini D, Wan X, Hirel CB, Salmon ED (2006) Aurora kinase promotes turnover of kinetochore microtubules to reduce chromosome segregation errors. Curr Biol 16:1711-1718

Cleveland DW, Mao Y, Sullivan KF (2003) Centromeres and kinetochores: from epigenetics to mitotic checkpoint signaling. Cell 112:407-421

DeLuca JG, Gall WE, Ciferri C, Cimini D, Musacchio A, Salmon ED (2006) Kinetochore microtubule dynamics and attachment stability are regulated by Hec1. Cell 127:969-982

Dewar H, Tanaka K, Nasmyth K, Tanaka TU (2004) Tension between two kinetochores suffices for their bi-orientation on the mitotic spindle. Nature 428:93-97

Ding R, McDonald KL, McIntosh JR (1993) Three-dimensional reconstruction and analysis of mitotic spindles from the yeast, Schizosaccharomyces pombe. J Cell Biol 120:141-151

Ditchfield C, Johnson VL, Tighe A, Ellston R, Haworth C, Johnson T, Mortlock A, Keen N, Taylor SS (2003) Aurora B couples 
chromosome alignment with anaphase by targeting BubR1, Mad2, and Cenp-E to kinetochores. J Cell Biol 161:267-280

Dobles M, Liberal V, Scott ML, Benezra R, Sorger PK (2000) Chromosome missegregation and apoptosis in mice lacking the mitotic checkpoint protein Mad2. Cell 101:635-645

Dong Y, Vanden Beldt KJ, Meng X, Khodjakov A, McEwen BF (2007) The outer plate in vertebrate kinetochores is a flexible network with multiple microtubule interactions. Nat Cell Biol 9:516-522

Dorer RK, Zhong S, Tallarico JA, Wong WH, Mitchison TJ, Murray AW (2005) A small-molecule inhibitor of Mps1 blocks the spindle-checkpoint response to a lack of tension on mitotic chromosomes. Curr Biol 15:1070-1076

Dorn JF, Jaqaman K, Rines DR, Jelson GS, Sorger PK, Danuser G (2005) Yeast kinetochore microtubule dynamics analyzed by high-resolution three-dimensional microscopy. Biophys $\mathrm{J}$ 89:2835-2854

Eckert CA, Gravdahl DJ, Megee PC (2007) The enhancement of pericentromeric cohesin association by conserved kinetochore components promotes high-fidelity chromosome segregation and is sensitive to microtubule-based tension. Genes Dev 21: 278-291

Efremov A, Grishchuk EL, McIntosh JR, Ataullakhanov FI (2007) In search of an optimal ring to couple microtubule depolymerization to processive chromosome motions. Proc Natl Acad Sci U S A 104:19017-19022

Emanuele MJ, Stukenberg PT (2007) Xenopus Cep57 is a novel kinetochore component involved in microtubule attachment. Cell 130:893-905

Endow SA (2003) Kinesin motors as molecular machines. Bioessays 25:1212-1219

Fernius J, Hardwick KG (2007) Bub1 kinase targets Sgol to ensure efficient chromosome biorientation in budding yeast mitosis. PLoS Genet 3:e213

Franck AD, Powers AF, Gestaut DR, Gonen T, Davis TN, Asbury CL (2007) Tension applied through the Dam1 complex promotes microtubule elongation providing a direct mechanism for length control in mitosis. Nat Cell Biol 9:832-837

Franco A, Meadows JC, Millar JB (2007) The Dam1/DASH complex is required for the retrieval of unclustered kinetochores in fission yeast. J Cell Sci 120:3345-3351

Gachet Y, Reyes C, Courtheoux T, Goldstone S, Gay G, Serrurier C, Tournier S (2008) Sister kinetochore recapture in fission yeast occurs by two distinct mechanisms, both requiring dam1 and klp2. Mol Biol Cell 19:1646-1662

Gadde S, Heald R (2004) Mechanisms and molecules of the mitotic spindle. Curr Biol 14:R797-805

Gestaut DR, Graczyk B, Cooper J, Widlund PO, Zelter A, Wordeman L, Asbury CL, Davis TN (2008) Phosphoregulation and depolymerization-driven movement of the Dam1 complex do not require ring formation. Nat Cell Biol 10:407-414

Gregan J, Riedel CG, Pidoux AL, Katou Y, Rumpf C, Schleiffer A, Kearsey SE, Shirahige K, Allshire RC, Nasmyth K (2007) The kinetochore proteins Pcs1 and Mde4 and heterochromatin are required to prevent merotelic orientation. Curr Biol 17:11901200

Grishchuk EL, Molodtsov MI, Ataullakhanov FI, McIntosh JR (2005) Force production by disassembling microtubules. Nature 438:384-388

Grishchuk EL, Spiridonov IS, Volkov VA, Efremov A, Westermann S, Drubin D, Barnes G, Ataullakhanov FI, McIntosh JR (2008) Different assemblies of the DAM1 complex follow shortening microtubules by distinct mechanisms. Proc Natl Acad Sci U S A 105:6918-6923

Hanisch A, Sillje HH, Nigg EA (2006) Timely anaphase onset requires a novel spindle and kinetochore complex comprising Ska1 and Ska2. Embo J 25:5504-5515
Hassold T, Hunt P (2001) To err (meiotically) is human: the genesis of human aneuploidy. Nat Rev Genet 2:280-291

Hauf S, Watanabe Y (2004) Kinetochore orientation in mitosis and meiosis. Cell 119:317-327

Hauf S, Cole RW, LaTerra S, Zimmer C, Schnapp G, Walter R, Heckel A, Van Meel J, Rieder CL, Peters JM (2003) The small molecule Hesperadin reveals a role for Aurora B in correcting kinetochoremicrotubule attachment and in maintaining the spindle assembly checkpoint. J Cell Biol 161:281-294

Hayashi I, Ikura M (2003) Crystal structure of the amino-terminal microtubule-binding domain of end-binding protein 1 (EB1). J Biol Chem 278:36430-36434

Hayden JH, Bowser SS, Rieder CL (1990) Kinetochores capture astral microtubules during chromosome attachment to the mitotic spindle: direct visualization in live newt lung cells. J Cell Biol 111:1039-1045

He X, Rines DR, Espelin CW, Sorger PK (2001) Molecular analysis of kinetochore-microtubule attachment in budding yeast. Cell 106:195-206

Hildebrandt ER, Hoyt MA (2000) Mitotic motors in Saccharomyces cerevisiae. Biochim Biophys Acta 1496:99-116

Howard J, Hyman AA (2007) Microtubule polymerases and depolymerases. Curr Opin Cell Biol 19:31-35

Indjeian VB, Murray AW (2007) Budding yeast mitotic chromosomes have an intrinsic bias to biorient on the spindle. Curr Biol 17:1837-1846

Indjeian VB, Stern BM, Murray AW (2005) The centromeric protein Sgol is required to sense lack of tension on mitotic chromosomes. Science 307:130-133

Janke C, Ortiz J, Tanaka TU, Lechner J, Schiebel E (2002) Four new subunits of the Dam1-Duo1 complex reveal novel functions in sister kinetochore biorientation. Embo J 21:181-193

Jelluma N, Brenkman AB, van den Broek NJ, Cruijsen CW, van Osch MH, Lens SM, Medema RH, Kops GJ (2008) Mps1 phosphorylates Borealin to control Aurora B activity and chromosome alignment. Cell 132(2):233-246

Joglekar AP, Bouck DC, Molk JN, Bloom KS, Salmon ED (2006) Molecular architecture of a kinetochore-microtubule attachment site. Nat Cell Biol 8:581-585

Joglekar AP, Bouck D, Finley K, Liu X, Wan Y, Berman J, He X, Salmon ED, Bloom KS (2008) Molecular architecture of the kinetochore-microtubule attachment site is conserved between point and regional centromeres. J Cell Biol 181:587-594

Jones MH, Huneycutt BJ, Pearson CG, Zhang C, Morgan G, Shokat K, Bloom K, Winey M (2005) Chemical genetics reveals a role for Mps1 kinase in kinetochore attachment during mitosis. Curr Biol 15:160-165

Kapoor TM, Lampson MA, Hergert P, Cameron L, Cimini D, Salmon ED, McEwen BF, Khodjakov A (2006) Chromosomes can congress to the metaphase plate before biorientation. Science 311:388-391

Kawashima SA, Tsukahara T, Langegger M, Hauf S, Kitajima TS, Watanabe Y (2007) Shugoshin enables tension-generating attachment of kinetochores by loading Aurora to centromeres. Genes Dev 21:420-435

Khodjakov A, Copenagle L, Gordon MB, Compton DA, Kapoor TM (2003) Minus-end capture of preformed kinetochore fibers contributes to spindle morphogenesis. J Cell Biol 160:671-683

King JM, Nicklas RB (2000) Tension on chromosomes increases the number of kinetochore microtubules but only within limits. J Cell Sci 113:3815-3823

King JM, Hays TS, Nicklas RB (2000) Dynein is a transient kinetochore component whose binding is regulated by microtubule attachment, not tension. J Cell Biol 151:739-748

King EM, Rachidi N, Morrice N, Hardwick KG, Stark MJ (2007) Ipl1p-dependent phosphorylation of Mad3p is required for the 
spindle checkpoint response to lack of tension at kinetochores. Genes Dev 21:1163-1168

Kirschner M, Mitchison T (1986) Beyond self-assembly: from microtubules to morphogenesis. Cell 45:329-342

Kitamura E, Tanaka K, Kitamura Y, Tanaka TU (2007) Kinetochoremicrotubule interaction during $\mathrm{S}$ phase in Saccharomyces cerevisiae. Genes Dev 21:3319-3330

Kiyomitsu T, Obuse C, Yanagida M (2007) Human Blinkin/AF15q14 is required for chromosome alignment and the mitotic checkpoint through direct interaction with Bub1 and BubR1. Dev Cell 13:663-676

Kline-Smith SL, Walczak CE (2004) Mitotic spindle assembly and chromosome segregation: refocusing on microtubule dynamics. Mol Cell 15:317-327

Knowlton AL, Lan W, Stukenberg PT (2006) Aurora B is enriched at merotelic attachment sites, where it regulates MCAK. Curr Biol 16:1705-1710

Kwok BH, Kapoor TM (2007) Microtubule flux: drivers wanted. Curr Opin Cell Biol 19:36-42

Lampson MA, Renduchitala K, Khodjakov A, Kapoor TM (2004) Correcting improper chromosome-spindle attachments during cell division. Nat Cell Biol 6:232-237

Lan W, Zhang X, Kline-Smith SL, Rosasco SE, Barrett-Wilt GA, Shabanowitz J, Hunt DF, Walczak CE, Stukenberg PT (2004) Aurora B phosphorylates centromeric MCAK and regulates its localization and microtubule depolymerization activity. Curr Biol $14: 273-286$

Liu J, Onuchic JN (2006) A driving and coupling "Pac-Man" mechanism for chromosome poleward translocation in anaphase A. Proc Natl Acad Sci U S A 103:18432-18437

Liu X, McLeod I, Anderson S, Yates JR, He X (2005) Molecular analysis of kinetochore architecture in fission yeast. Embo J 24:2919-2930

Loncarek J, Kisurina-Evgenieva O, Vinogradova T, Hergert P, La Terra S, Kapoor TM, Khodjakov A (2007) The centromere geometry essential for keeping mitosis error free is controlled by spindle forces. Nature 450:745-749

Losada A, Hirano M, Hirano T (2002) Cohesin release is required for sister chromatid resolution, but not for condensin-mediated compaction, at the onset of mitosis. Genes Dev 16:3004-3016

Maiato H, Deluca J, Salmon ED, Earnshaw WC (2004a) The dynamic kinetochore-microtubule interface. J Cell Sci 117:5461-5477

Maiato H, Rieder CL, Khodjakov A (2004b) Kinetochore-driven formation of kinetochore fibers contributes to spindle assembly during animal mitosis. J Cell Biol 167:831-840

Marston AL, Amon A (2004) Meiosis: cell-cycle controls shuffle and deal. Nat Rev Mol Cell Biol 5:983-997

Maure JF, Kitamura E, Tanaka TU (2007) Mps1 kinase promotes sister-kinetochore bi-orientation by a tension-dependent mechanism. Curr Biol 17:2175-2182

McDonald KL, O'Toole ET, Mastronarde DN, McIntosh JR (1992) Kinetochore microtubules in PTK cells. J Cell Biol 118:369-383

Meraldi P, Sorger PK (2005) A dual role for Bub1 in the spindle checkpoint and chromosome congression. EMBO J 24:16211633

Meraldi P, McAinsh AD, Rheinbay E, Sorger PK (2006) Phylogenetic and structural analysis of centromeric DNA and kinetochore proteins. Genome Biol 7:R23

Miranda JJ, De Wulf P, Sorger PK, Harrison SC (2005) The yeast DASH complex forms closed rings on microtubules. Nat Struct Mol Biol 12:138-143

Morrow CJ, Tighe A, Johnson VL, Scott MI, Ditchfield C, Taylor SS (2005) Bub1 and aurora B cooperate to maintain BubR1mediated inhibition of APC/CCdc20. J Cell Sci 118:3639-3652

Musacchio A, Salmon ED (2007) The spindle-assembly checkpoint in space and time. Nat Rev Mol Cell Biol 8:379-393
Nasmyth K (2002) Segregating sister genomes: the molecular biology of chromosome separation. Science 297:559-565

Nicklas RB (1997) How cells get the right chromosomes. Science 275:632-637

Nicklas RB, Koch CA (1969) Chromosome micromanipulation. 3. Spindle fiber tension and the reorientation of mal-oriented chromosomes. J Cell Biol 43:40-50

Ocampo-Hafalla MT, Katou Y, Shirahige K, Uhlmann F (2007) Displacement and re-accumulation of centromeric cohesin during transient pre-anaphase centromere splitting. Chromosoma 116:531-544

Ohi R, Coughlin ML, Lane WS, Mitchison TJ (2003) An inner centromere protein that stimulates the microtubule depolymerizing activity of a KinI kinesin. Dev Cell 5:309-321

Ohi R, Sapra T, Howard J, Mitchison TJ (2004) Differentiation of cytoplasmic and meiotic spindle assembly MCAK functions by Aurora B-dependent phosphorylation. Mol Biol Cell 15:28952906

Parry DH, Hickson GR, O'Farrell PH (2003) Cyclin B destruction triggers changes in kinetochore behavior essential for successful anaphase. Curr Biol 13:647-653

Pearson CG, Yeh E, Gardner M, Odde D, Salmon ED, Bloom K (2004) Stable kinetochore-microtubule attachment constrains centromere positioning in metaphase. Curr Biol 14:1962-1967

Pereira G, Schiebel E (2003) Separase regulates INCENP-Aurora B anaphase spindle function through Cdc14. Science 302:2120-2124

Pinsky BA, Kung C, Shokat KM, Biggins S (2006) The Ipl1-Aurora protein kinase activates the spindle checkpoint by creating unattached kinetochores. Nat Cell Biol 8:78-83

Porter IM, Swedlow JR (2007) Bod1, a novel kinetochore protein required for chromosome biorientation. J Cell Biol 179(2):187-197

Rajagopalan H, Lengauer C (2004) Aneuploidy and cancer. Nature 432:338-341

Rieder CL (2005) Kinetochore fiber formation in animal somatic cells: dueling mechanisms come to a draw. Chromosoma 114:310-318

Rieder CL, Alexander SP (1990) Kinetochores are transported poleward along a single astral microtubule during chromosome attachment to the spindle in newt lung cells. J Cell Biol 110:81-95

Rogers GC, Rogers SL, Sharp DJ (2005) Spindle microtubules in flux. J Cell Sci 118:1105-1116

Rosasco-Nitcher SE, Lan W, Khorasanizadeh S, Stukenberg PT (2008) Centromeric Aurora-B activation requires TD-60, microtubules, and substrate priming phosphorylation. Science 319:469-472

Ruchaud S, Carmena M, Earnshaw WC (2007) Chromosomal passengers: conducting cell division. Nat Rev Mol Cell Biol 8:798-812

Sanchez-Perez I, Renwick SJ, Crawley K, Karig I, Buck V, Meadows JC, Franco-Sanchez A, Fleig U, Toda T, Millar JB (2005) The DASH complex and Klp5/Klp6 kinesin coordinate bipolar chromosome attachment in fission yeast. Embo J 24: 2931-2943

Sandall S, Severin F, McLeod IX, Yates JR 3rd, Oegema K, Hyman A, Desai A (2006) A Bir1-Sli15 complex connects centromeres to microtubules and is required to sense kinetochore tension. Cell 127:1179-1191

Sazer S (2005) Nuclear envelope: nuclear pore complexity. Curr Biol 15:R23-26

Shang C, Hazbun TR, Cheeseman IM, Aranda J, Fields S, Drubin DG, Barnes G (2003) Kinetochore protein interactions and their regulation by the Aurora kinase Ipl1p. Mol Biol Cell 14:33423355

Sonoda E, Matsusaka T, Morrison C, Vagnarelli P, Hoshi O, Ushiki T, Nojima K, Fukagawa T, Waizenegger IC, Peters JM, Earnshaw WC, Takeda S (2001) Scc1/Rad21/Mcd1 is required for sister chromatid cohesion and kinetochore function in vertebrate cells. Dev Cell 1:759-770 
Tanaka TU, Desai A (2008) Kinetochore-microtubule interactions: the means to the end. Curr Opin Cell Biol 20:53-63

Tanaka T, Fuchs J, Loidl J, Nasmyth K (2000) Cohesin ensures bipolar attachment of microtubules to sister centromeres and resists their precocious separation. Nat Cell Biol 2:492-499

Tanaka TU, Rachidi N, Janke C, Pereira G, Galova M, Schiebel E, Stark MJ, Nasmyth K (2002) Evidence that the Ipl1-Sli15 (Aurora kinase-INCENP) complex promotes chromosome biorientation by altering kinetochore-spindle pole connections. Cell 108:317-329

Tanaka K, Mukae N, Dewar H, van Breugel M, James EK, Prescott AR, Antony C, Tanaka TU (2005a) Molecular mechanisms of kinetochore capture by spindle microtubules. Nature 434:987-994

Tanaka TU, Stark MJ, Tanaka K (2005b) Kinetochore capture and biorientation on the mitotic spindle. Nat Rev Mol Cell Biol 6:929-942

Tanaka K, Kitamura E, Kitamura Y, Tanaka TU (2007) Molecular mechanisms of microtubule-dependent kinetochore transport toward spindle poles. J Cell Biol 178:269-281

Vagnarelli P, Morrison C, Dodson H, Sonoda E, Takeda S, Earnshaw WC (2004) Analysis of Scc1-deficient cells defines a key metaphase role of vertebrate cohesin in linking sister kinetochores. EMBO Rep 5:167-171

Vanoosthuyse V, Prykhozhij S, Hardwick KG (2007) Shugoshin 2 regulates localization of the chromosomal passenger proteins in fission yeast mitosis. Mol Biol Cell 18:1657-1669

Wang HW, Ramey VH, Westermann S, Leschziner AE, Welburn JP, Nakajima Y, Drubin DG, Barnes G, Nogales E (2007) Architecture of the Dam1 kinetochore ring complex and implications for microtubule-driven assembly and force-coupling mechanisms. Nat Struct Mol Biol 14:721-726

Warren CD, Brady DM, Johnston RC, Hanna JS, Hardwick KG, Spencer FA (2002) Distinct chromosome segregation roles for spindle checkpoint proteins. Mol Biol Cell 13:3029-3041

Wei RR, Sorger PK, Harrison SC (2005) Molecular organization of the Ndc80 complex, an essential kinetochore component. Proc Natl Acad Sci U S A 102:5363-5367

Wei RR, Schnell JR, Larsen NA, Sorger PK, Chou JJ, Harrison SC (2006) Structure of a central component of the yeast kinetochore: the Spc24p/Spc25p globular domain. Structure 14:1003-1009

Wei RR, Al-Bassam J, Harrison SC (2007) The Ndc80/HEC1 complex is a contact point for kinetochore-microtubule attachment. Nat Struct Mol Biol 14:54-59
Weiss E, Winey M (1996) The Saccharomyces cerevisiae spindle pole body duplication gene MPS1 is part of a mitotic checkpoint. J Cell Biol 132:111-123

Westermann S, Avila-Sakar A, Wang HW, Niederstrasser H, Wong J, Drubin DG, Nogales E, Barnes G (2005) Formation of a dynamic kinetochore-microtubule interface through assembly of the Dam1 ring complex. Mol Cell 17:277-290

Westermann S, Wang HW, Avila-Sakar A, Drubin DG, Nogales E, Barnes G (2006) The Dam1 kinetochore ring complex moves processively on depolymerizing microtubule ends. Nature 440:565-569

Westermann S, Drubin DG, Barnes G (2007) Structures and functions of yeast kinetochore complexes. Annu Rev Biochem 76:563-591

Winey M, O'Toole ET (2001) The spindle cycle in budding yeast. Nat Cell Biol 3:E23-27

Winey M, Huneycutt BJ (2002) Centrosomes and checkpoints: the MPS1 family of kinases. Oncogene 21:6161-6169

Winey M, Mamay CL, O’Toole ET, Mastronarde DN, Giddings TH Jr, McDonald KL, McIntosh JR (1995) Three-dimensional ultrastructural analysis of the Saccharomyces cerevisiae mitotic spindle. J Cell Biol 129:1601-1615

Wollman R, Cytrynbaum EN, Jones JT, Meyer T, Scholey JM, Mogilner A (2005) Efficient chromosome capture requires a bias in the 'search-and-capture' process during mitotic-spindle assembly. Curr Biol 15:828-832

Wong J, Nakajima Y, Westermann S, Shang C, Kang JS, Goodner C, Houshmand P, Fields S, Chan CS, Drubin D, Barnes G, Hazbun $\mathrm{T}$ (2007) A protein interaction map of the mitotic spindle. Mol Biol Cell 18:3800-3809

Yang Z, Tulu US, Wadsworth P, Rieder CL (2007) Kinetochore dynein is required for chromosome motion and congression independent of the spindle checkpoint. Curr Biol 17:973-980

Yeh E, Haase J, Paliulis LV, Joglekar A, Bond L, Bouck D, Salmon ED, Bloom KS (2008) Pericentric chromatin is organized into an intramolecular loop in mitosis. Curr Biol 18:81-90

Zhang K, Lin W, Latham JA, Riefler GM, Schumacher JM, Chan C, Tatchell K, Hawke DH, Kobayashi R, Dent SY (2005) The Set1 methyltransferase opposes Ipl1 aurora kinase functions in chromosome segregation. Cell 122:723-734

Zhang X, Lan W, Ems-McClung SC, Stukenberg PT, Walczak CE (2007) Aurora B phosphorylates multiple sites on mitotic centromere-associated kinesin to spatially and temporally regulate its function. Mol Biol Cell 18:3264-3276 